\title{
AVALIAÇÃO DA EFICIÊNCIA DE BETERRABAS ORGÂNICAS NÃO CONFORMES À COMERCIALIZAÇÃO NA PRODUÇÃO DE FARINHAS: MODELO DE SUSTENTABILIDADE PARA AGROINDÚSTRIA FAMILIAR RURAL, RS, BRASIL
}

\author{
Claimeri Pasa* \\ Patrícia Braga Lovatto** \\ Michele Hoeltz*** \\ Bruno Engel ${ }^{* * * *}$ \\ Ana Lúcia Becker Rohlfes ${ }^{* * * * *}$ \\ Eduardo Alcayaga Lobo ${ }^{* * * * * *}$
}

RESUMO: Considerando a quantidade de vegetais não conformes à comercialização desperdiçados em entrepostos e feiras livres, configurando perdas nutricionais e de renda, bem como a destinação final inadequada no ambiente, a pesquisa objetivou avaliar a eficiência da reutilização da beterraba orgânica não conforme na produção de farinha. Realizou-se a análise da composição centesimal da beterraba conforme e não conforme, para tempos de secagem ( $2 \mathrm{~h}, 5 \mathrm{~h}, 7 \mathrm{~h}$ e $9 \mathrm{~h})$, a $75^{\circ} \mathrm{C}$. O tempo de $2 \mathrm{~h}$ resultou o mais adequado, considerando os custos para uma agroindústria familiar, tendo apresentado valores de umidade conforme os padróes. Houve um aumento nos teores de fibras, proteínas e cinzas, caracterizando uma farinha de alto valor nutritivo. A análise da palatabilidade da massa com $25 \%$ de farinha de beterraba não conforme, adicionada à farinha de trigo, revelou um elevado grau de aceitabilidade. A reutilização de resíduos vegetais orgânicos não conformes pode se tornar uma fonte de renda, além de contribuir para sustentabilidade.

PALAVRAS-CHAVE: Agroindústria familiar rural; Reaproveitamento de alimentos; Valor nutricional.

\footnotetext{
Mestre em Tecnologia Ambiental pela Universidade de Santa Cruz do Sul (UNISC), Brasil; E-mail: claimeripasaufsm@gmail.com

** Doutora, Pesquisadora do Programa de Pós-Graduação em Sistemas de Produção Agrícola Familiar da Universidade Federal de Pelotas (UFPEL) DocFix FAPERGES/CAPES

${ }^{* * *}$ Doutora, Pesquisadora do Programa de Pós-Graduação em Tecnologia Ambiental (PPGTA/UNISC), Brasil.

${ }^{* * * *}$ Discente do Curso de Química e Física da Universidade de Santa Cruz do Sul (UNISC), Brasil

${ }^{* * * * *}$ Doutora, Pesquisadora do Departamento de Química Industrial da Universidade de Santa Cruz do Sul (UNISC), Brasil

${ }^{* * * * * *}$ Doutor, Pesquisador do Programa de Pós-Graduação em Tecnologia Ambiental (PPGTA/UNISC), Brasil.
} 


\section{EVALUATION OF THE EFFICIENCY OF NON-COMMERCIALIZED ORGANIC BEETROOT IN FLOUR PRODUCTION: SUSTAINABILITY MODEL FOR FAMILY AGRIBUSINESS IN BRAZIL}

ABSTRACT: Due to the great number of vegetables which do not comply with commercialization patterns and are wasted in depots and fairs, with nutritional and profit loss, coupled to inadequate disposal in the environment, current research assesses the efficiency of the re-use of organic beetroot in flour production. The chemical composition of non-commercialized and commercialized beetroot was analyzed for drying periods $(2 \mathrm{~h}, 5 \mathrm{~h}, 7 \mathrm{~h}$ and $9 \mathrm{~h})$ at $75^{\circ} \mathrm{C}$. The $2 \mathrm{~h}$ period proved to be adequate when costs for a family agribusiness are taken into account due to standard humidity. Fiber, protein and ash rates increased and the flour was characterized as highly nutritional. Taste analysis with $25 \%$ beetroot flour added to wheat flour proved to be greatly acceptable. The re-use of non-adequate vegetable wastes may be a source of income and may contribute to sustainability.

KEY WORDS: Family agribusiness; Re-use of food; Nutritional value.

\section{INTRODUÇÃO}

Perdas e desperdícios de alimentos impactam os sistemas de produção em distintos cenários da cadeia alimentar, reduzindo a disponibilidade local e global de alimentos, gerando perdas de renda para produtores, elevando preços para consumidores e afetando o meio ambiente devido ao uso insustentável dos recursos naturais (FAO, 2014).

A agroindústria familiar rural é uma unidade de processamento de alimentos dentro ou próxima das propriedades rurais, podendo ser individual ou associadas com tecnologias simples e condições favoráveis ao resgate de saberes e práticas tradicionais (SGARBI et al., 2007).

O plantio de hortaliças é uma atividade comum nestas propriedades utilizadas na alimentação familiar e para a comercialização em feiras livres ou destinadas ao mercado institucional através do Programa Nacional de Alimentação Escolar (PNAE), que estimula a aquisição de alimentos do setor agrícola familiar (CAMARGO et al., 2013). 
Para a distribuição destes alimentos aos diferentes segmentos, deve ser observado o padrão de comercialização exigido pelo mercado hortifrutigranjeiro, conforme Lei $n^{0} 9.972 / 2000$, aperfeiçoada pelo Decreto $n^{0}$ 6.268/2007 (BRASIL, 2007), uma vez que características como injúrias mecânicas, deformidades, alterações na cor, peso ou tamanho e aparecimento de pontos pretos, entre outras, determinam a não-conformidade de venda destes produtos (ZANATTA et al., 2010).

Entretanto, muitos destes alimentos ainda constituem fonte de nutrientes e poderiam ser empregados na alimentação de modo alternativo ao consumo in natura, como na forma de farinhas, processo que vem se destacando na indústria brasileira de reaproveitamento de vegetais não conformes (LOPES et al., 2011).

O consumo de hortaliças é motivado pelo significativo valor nutricional, possibilitando uma vida mais saudável e aumentando, assim, a demanda pelos consumidores. Em tal sentido, por serem produtos altamente perecíveis são apontados como maiores perdas em toda a cadeia produtiva (CECCATO; BASSO, 2011).

De acordo com Miguel et al. (2008), os resíduos vegetais podem ser utilizados como fertilizantes orgânicos e na alimentação animal. A qualidade de um composto orgânico é fator preponderante para a "saúde do sistema solo-água-arplanta" e não pode ser usado sem tratamento prévio, como a compostagem. Nesse sentido, se faz necessária a redução do desperdício na fonte de origem, o produtor, levando em conta ainda que resíduos vegetais nobres poderiam ser reutilizados (ABREU JUNIOR et al., 2005).

No Brasil, a cada dez toneladas de alimentos produzidas, apenas quatro chegam aos pratos dos brasileiros (COSTA, 2013). O restante dos alimentos é tido como refugos em entrepostos, mercados e centros de produção, devido, principalmente, às colheitas excessivas ou encalhadas, à falta de cuidado no transporte e o despreparo dos comerciantes (SCHEEREN, 2011).

Considerando as perdas pós-colheitas, é possível reutilizar os alimentos que ainda possuem alto valor nutritivo e microbiologicamente seguros, podendo se aplicar o terceiro princípio da Política Nacional de Resíduos Sólidos (PNRS), Lei 12.305/2010 (BRASIL, 2010), que preconiza a reutilização para atingir o mínimo possível de resíduos vegetais, contribuindo para a segurança e soberania alimentar, 
minimizando o desperdício de alimentos.

Segundo Araújo Filho et al. (2011), a produção de farinhas a base de vegetais não conformes à comercialização é possível utilizando processos tecnológicos simples e disponíveis para grande parte dos agricultores familiares. A Resolução no 12/1978 da Comissão Nacional de Normas e Padrões para Alimentos (CNNPA) (BRASIL, 1978) especifica o uso de farinhas de vegetais como sendo "produto obtido pela moagem da parte comestível, podendo sofrer processos tecnológicos adequados".

Nesse sentido, a beterraba, beterraba vermelha ou beterraba de mesa (Beta vulgaris L.) é uma das principais hortaliças cultivadas no Brasil, com diversos biótipos, cujas raízes e folhas são utilizadas na alimentação humana (TIVELLI et al., 2011). O Censo Agropecuário (IBGE, 2009) apontou que existiam 21.937 estabelecimentos agrícolas que produziram 177.154 toneladas/ano de beterraba no Rio Grande do Sul (RS) e que este estava entre os seis maiores produtores da hortícola. A beterraba está presente em cerca de 100 mil propriedades rurais no Brasil, ocupando área equivalente a 10 mil hectares, com a produção de 300 mil toneladas/ano (SEBRAE, 2011).

Bassi (2014) destaca, entre os benefícios do consumo da beterraba, o fato dela ser um auxiliar na redução da pressão arterial, ótimo antioxidante natural, agindo contra o envelhecimento celular e reduzindo o risco de alguns tipos de câncer, rica em vitamina A e vitaminas do complexo B, importantes para o sistema imunológico, incluindo o ácido fólico, relacionado à boa formação fetal, e vitamina C, que possui ação antioxidante e atuação benéfica sobre o sistema imunológico. Se a hortaliça for cultivada com adição de agrotóxicos pode vir a causar reações adversas. Para tanto, existe o órgão regulador que avalia a qualidade dos alimentos, o Programa de Análise de Resíduos de Agrotóxicos em Alimentos (PARA), criado pela Agência Nacional de Vigilância Sanitária (ANVISA) (SANTOS et al., 2014).

Por estes motivos, a beterraba orgânica foi escolhida como objeto deste estudo, quando não conforme à comercialização, visando à utilização como matériaprima para elaboração de farinhas vegetais na agroindústria familiar, considerando que os agricultores familiares são os principais responsáveis pela produção de alimentos orgânicos do Brasil (SANTOS et al., 2014) e o PNAE prioriza a aquisição de alimentos para a merenda escolar com cultivo orgânico. 
Conforme dados de produtores de Santa Cruz do Sul (RS), associados à Cooperativa Regional de Agricultores Familiares Ecologistas (ECOVALE), associação que segundo Picoli (2013) privilegia a produção ecológica, são comercializados em torno de $60 \mathrm{~kg}$ de vegetais por semana na feira livre, destacando que após a classificação dos vegetais para a venda na propriedade, gera-se um resíduo de $10 \%$ do total. Ainda, dos $60 \mathrm{~kg}$ a serem comercializados, gera-se um resíduo de 5\% da venda, totalizando uma perda de $15 \%$ semanais.

Na região do COREDE, Vale do Rio Pardo (RS), distintos processos de produção de farinhas vegetais têm sido utilizados nas empresas alimentícias, destacando que a secagem por estufa caracteriza-se como um dos processos mais frequentemente utilizados na agricultura familiar. Neste contexto, visando otimizar o processo de produção de farinha vegetal a nível regional (secagem por estufa), a presente pesquisa objetivou avaliar a eficiência da beterraba orgânica não conforme à comercialização, submetendo o vegetal a distintos processos de beneficiamento (tempo, temperatura e cominuição), visando selecionar o sistema de produção que apresente o maior custo/benefício para implantação nas agroindústrias rurais familiares da região e sua aceitabilidade em massa de talharim.

\section{MATERIAL E MÉTODOS}

\subsection{DETERMINAÇÃO FÍSICO-QUÍMICA DA BETERRABA ORGÂNICA NÃO CONFORME}

\subsubsection{Amostras}

A matéria-prima utilizada foi adquirida a partir da feira da ECOVALE de Santa Cruz do Sul (RS), Brasil. Foram adquiridos em março de 2014, 3,720 kg de beterraba in natura, padrão conforme, e 1,258 kg de beterraba não conforme, perfazendo um total de $5 \mathrm{~kg}$ o que resultou em $500 \mathrm{~g}$ de farinha. Os tubérculos foram lavados, descascados a fim de remover injúrias, podridões e pontos pretos, conforme sugerido por Zanatta et al. (2010). Em seguida foram feitos dois tipos de cominuição 
(fatiada e ralada) nas beterrabas, que foram colocadas em um desidratador com circulação de ar forçada, a uma temperatura constante de $75^{\circ} \mathrm{C}$, pois Araújo Filho et al. (2011) sugerem temperaturas entre $70^{\circ} \mathrm{C}$ a $100{ }^{\circ} \mathrm{C}$, por não apresentarem diferenças significativas na secagem.

As amostras da beterraba in natura fatiadas ficaram no desidratador por períodos de $5 \mathrm{~h}, 7 \mathrm{~h}$ e $9 \mathrm{~h}$, enquanto as amostras raladas in natura por $2 \mathrm{~h}$ e $5 \mathrm{~h}$. Repetiu-se o procedimento com amostras das beterrabas não conformes fatiadas por períodos de $5 \mathrm{~h}, 7 \mathrm{~h}$ e $9 \mathrm{~h}$. Em seguida as amostras foram trituradas até a consistência de pó com auxílio de um liquidificador. As amostras foram colocadas em frascos e seguiram para análise da composição centesimal.

$O$ tratamento das amostras feitas em triplicata para cada tempo e a realização das técnicas de análise e de quantificação foi feito no Laboratório de Ciências dos Alimentos (LACIAL) e Laboratório de Tecnologia de Produtos Vegetais da Universidade de Santa Cruz do Sul (UNISC).

\subsubsection{ANÁLISE CENTESIMAL DAS FARINHAS}

Os parâmetros físicos e químicos foram avaliados de acordo com as normas do Instituto Adolfo Lutz (2008). Todas as amostras foram analisadas em triplicata para: umidade (secagem em estufa, $105^{\circ} \mathrm{C}$ ), cinzas (destruição da matéria orgânica em mufla a $550{ }^{\circ} \mathrm{C}$ ), fibras (método de Weender, digestão ácida e básica), lipídios (método adaptado Bligh-Dyer), proteínas (método Kjeldahl) e carboidratos (carboidratos totais pela diferença).

\subsubsection{PROCESSAMENTO DOS DADOS}

Para o processamento da informação, empregaram-se as provas estatísticas não-paramétricas de Kruskall-Wallis, seguido do teste de comparações múltiplas de Dunn, bem como a prova de Mann-Whitney (CALLEGARI-JACQUES, 2006), $\operatorname{com} \alpha=$ 0.05. Utilizou-se o programa estatístico GraphpadInstat v. 3.00. 


\subsection{PRODUÇÃO DA MASSA DE TALHARIM COM FARINHA DE BETERRABA ORGÂNI- CA NÃO CONFORME}

A segunda etapa foi executada na Agroindústria Rural Familiar Santa Isabel (parceira do presente trabalho), localizada no bairro de Santa Lúcia, município de Ibarama (RS) - pertencente ao COREDE Vale do Rio Pardo (RS). As melhores condições de tempo, temperatura e cominuição obtidas em laboratório foram aplicadas para a elaboração da farinha de beterraba. Foram feitos testes com adição progressiva de farinha de beterraba, 50\% e 25\%, em substituição à farinha de trigo. O experimento com $25 \%$ de farinha de beterraba conseguiu o melhor resultado. A massa foi preparada com o auxílio da máquina industrial misturadora disponível, utilizando farinha de trigo especial para massas e ovos. Considerando que a medida utilizada normalmente na agroindústria para produzir $5 \mathrm{~kg}$ de massa é de $5 \mathrm{~kg}$ de farinha de trigo especial e 30 ovos, a massa produzida experimentalmente utilizou $1,5 \mathrm{~kg}$ de farinha de beterraba (25\%), 3,5 kg de farinha de trigo (75\%) e 30 ovos, resultando igualmente em $5 \mathrm{~kg}$ de massa. Essa massa foi utilizada na fabricação de talharim.

\subsection{ANÁLISE SENSORIAL DA MASSA DE TALHARIM COM 25\% DE FARINHA DE BETERRABA ORGÂNICA NÃO CONFORME}

Visando avaliar a aceitabilidade pelo potencial público consumidor, em termos da palatabilidade (sabor) da massa de talharim (cozida em água e sal e adicionada de molho de frango e tomate) elaborada com adição da farinha de beterraba orgânica não conforme, foi realizada uma análise sensorial em ambiente climatizado, no horário de almoço (12h), que contou com a participação de provadores adultos $(\mathrm{n}=12)$, em uma faixa etária que variou de 19 até 67 anos. A escala hedônica verbal de cinco pontos de palatabilidade utilizada incluiu as seguintes categorias: gostei muito, gostei ligeiramente, indiferente, desgostei ligeiramente, desgostei muito, seguindo as recomendações de Neves e Lima (2010). 


\section{RESULTADOS E DISCUSSÃO}

\subsection{ANÁLISE DA BETERRABA ORGÂNICA FATIADA E RALADA SEGUNDO OS TEM- POS DE DESIDRATAÇÃO E PRODUÇÃO DA FARINHA}

A determinação do percentual de umidade é uma das mais importantes variáveis utilizadas na análise de alimentos, pois está relacionada com sua estabilidade, qualidade e composição (PARK; ANTONIO, 2006).

A partir dos dados apresentados na Figura 1, foi verificada uma diferença significativa apenas para os tempos de desidratação da beterraba in natura fatiada conforme de 5 e 9 horas $(p<0.05)$, caracterizando os tempos de 7 e 9 horas como adequados para a produção de farinha, considerando que os valores obtidos coincidem com o valor de umidade recomendado para secagem por Guimarães e Seibel (2009) e ANVISA (1996), sendo igual ou inferior a 15\%.

Como se observa na Figura 2, a mesma condição foi verificada para os tempos de desidratação da beterraba fatiada não conforme à comercialização. Em ambos os casos (Figuras 1 e 2) houve diferenças significativas para os mesmos tempos de desidratação, caracterizando, portanto, os tempos de 7 e 9 horas como adequados para a produção de farinha. Ainda comparando os distintos tempos de desidratação da polpa de beterraba em amostras conformes e não conformes à comercialização, verificou-se que não houve diferenças significativas entre as mesmas $(p=0.3865)$, chancelando, portanto, a viabilidade da produção de farinha a partir de beterrabas não conformes à comercialização.

Contudo, os tempos de desidratação da polpa da beterraba recomendados para a fabricação de farinhas, de 7 e 9 horas, não eram viáveis para uma agroindústria familiar, com vista à utilização desta matéria-prima para fabricação de massas, devido ao gasto de energia e tempo de ocupação do forno de secagem, evitando a utilização deste para fabricação de outros produtos, e assim tornando os custos operacionais do tratamento elevados. A avaliação de novos formatos de corte do tubérculo pode ser importante no sentido de melhorar o rendimento e o tempo de secagem, no intuito de facilitar a remoção de água do vegetal. Desta forma, um novo experimento foi conduzido utilizando a polpa da beterraba ralada, para dois tempos de desidratação: 2 horas e 5 horas. 


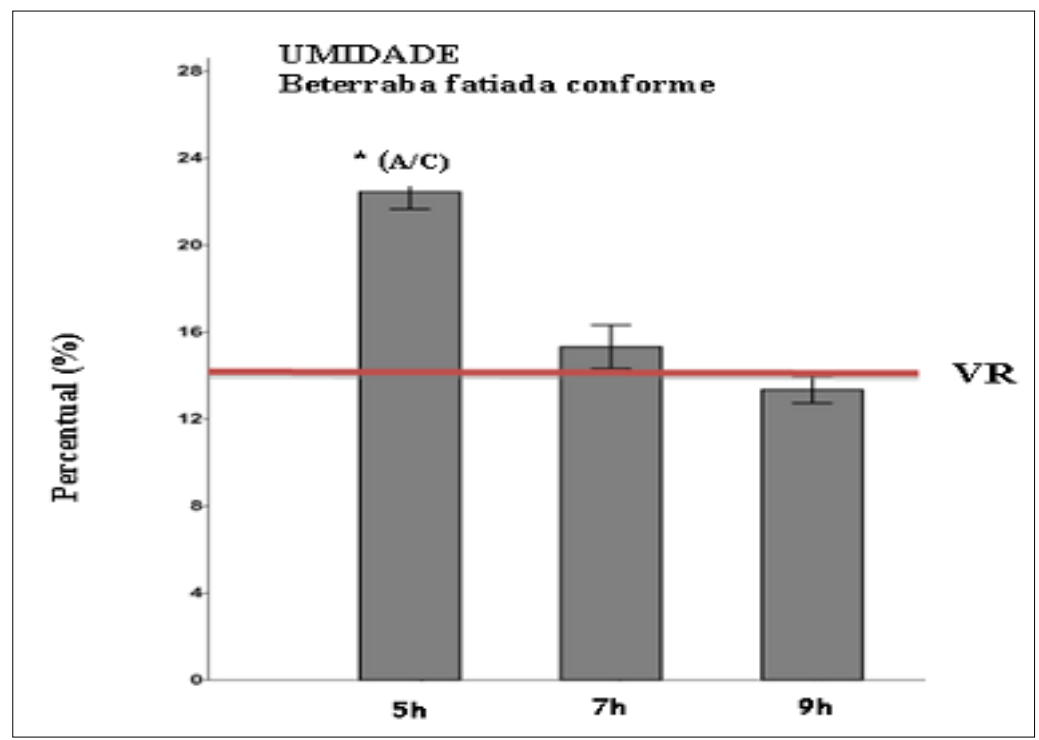

Figura 1. Valores médios de triplicatas ( \pm desvio-padrão) do percentual de umidade (\%) para três tempos de desidratação da polpa da beterraba conforme, fatiada, de 5 horas, 7 horas e 9 horas. * diferença significativa $(p<0.05)$. VR: Valor Recomendado para secagem $(=<15,0 \%)$, seguindo Guimarães e Seibel (2009) e ANVISA (1996). Laboratório de Tecnologia de Produtos Vegetais, Universidade de Santa Cruz do Sul - UNISC, Santa Cruz do Sul, abril de 2014.

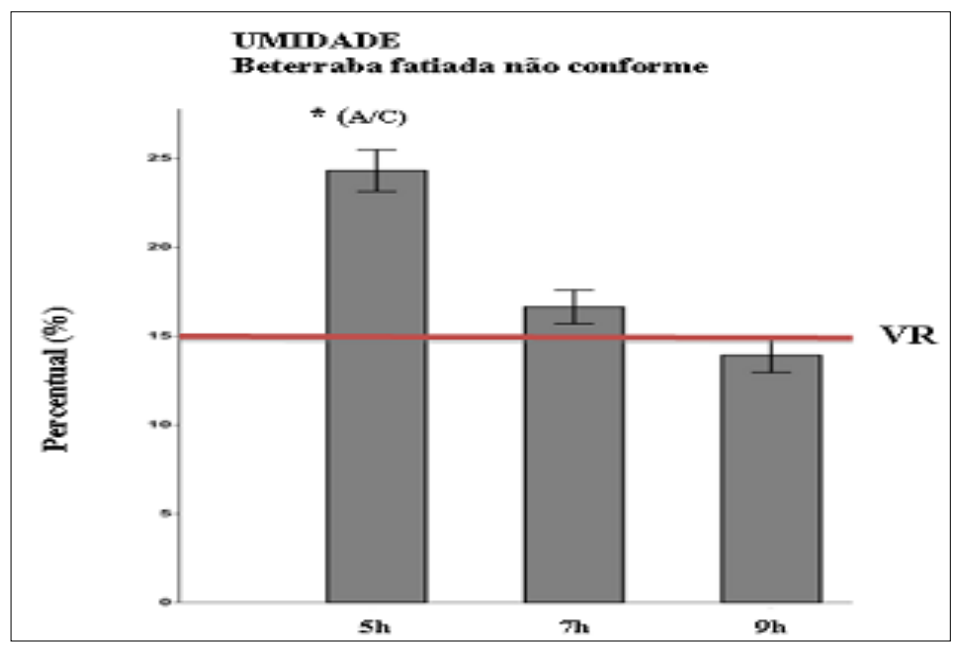

Figura 2. Valores médios de triplicatas ( \pm desvio-padrão) do percentual de umidade (\%) para três tempos de desidratação da polpa da beterraba não conforme à comercialização, fatiada, de 5 horas, 7 horas e 9 horas. * diferença significativa $(p<0.05)$. VR: Valor Recomendado para secagem $(=<$ 15,0\%), seguindo Guimarães e Seibel (2009) e ANVISA (1996). Laboratório de Tecnologia de Produtos Vegetais, Universidade de Santa Cruz do Sul - UNISC, Santa Cruz do Sul, abril de 2014. 
Os resultados apresentados na Figura 3 indicaram que não houve diferenças significativas entre os tempos de 2 e 5 horas $(p>0.05)$ e que ambos os valores estiveram dentro do recomendado para secagem, qual seja uma umidade igual ou inferior a 15\% (GUIMARÃES; SEIBEL, 2009; ANVISA, 1996). Ainda comparando com os resultados de Zimmermann et al. (2009) para o teor de umidade de diferentes marcas de farinhas de trigo, que variou entre 11,6\% e 13,6\%, verificou-se a viabilidade da utilização da farinha de beterraba orgânica conforme e não conforme à comercialização. Desta forma, optou-se por recomendar o tempo de 2 horas para a sua utilização na agricultura familiar, considerando sua viabilidade em termos operacionais.

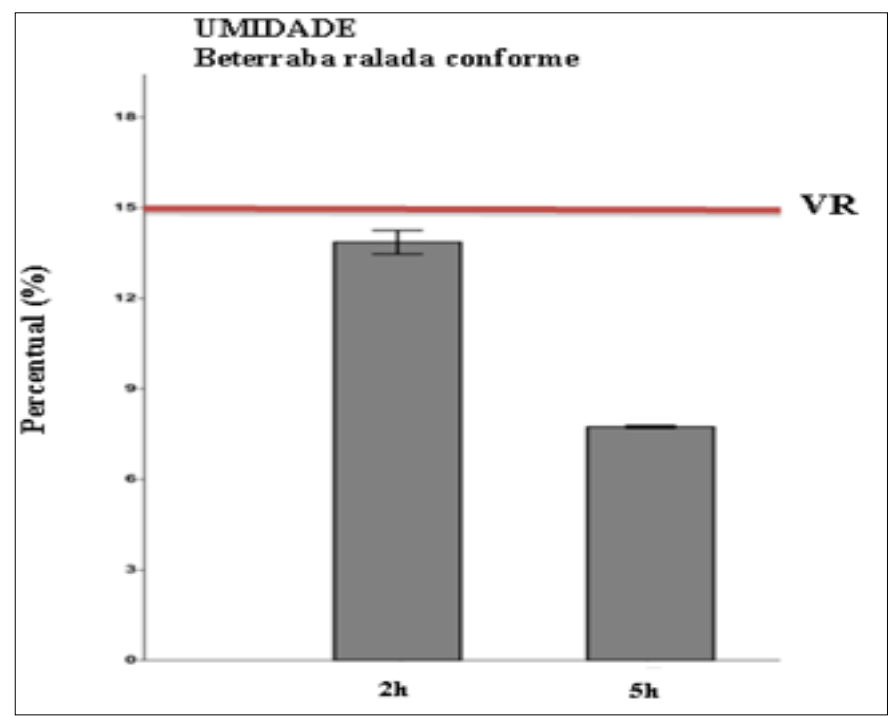

Figura 3. Valores médios de triplicatas ( \pm desvio-padrão) do percentual de umidade (\%) para dois tempos de desidratação da polpa da beterraba conforme, ralada, de 2 horas e 5 horas. Não há diferenças significativas $(p>0.05)$. VR: Valor Recomendado para secagem $(=<15,0 \%)$, seguindo Guimarães e Seibel (2009) e ANVISA (1996). Laboratório de Tecnologia de Produtos Vegetais, Universidade de Santa Cruz do Sul - UNISC, Santa Cruz do Sul, maio de 2014.

Nos resultados da determinação das variáveis cinza, fibras, lipídios, proteínas, carboidratos e valor energético (Tabela 1), comparando amostras conformes com não conformes, houve diferenças significativas $(p<0.05)$ para fibras e proteínas da farinha da beterraba orgânica fatiada não conforme à comercialização nos tempos de 5 e 9 horas, chancelando novamente a viabilidade dos tempos de secagem de 7 e 9 
horas de tal forma que possam ser utilizadas na agroindústria familiar. Contudo, esses tempos não são viáveis para uma unidade agrícola familiar, conforme já discutido. Assim, da mesma forma, determinaram-se as variáveis da composição centesimal da farinha de beterraba ralada, em dois tempos de desidratação ( 2 horas e 5 horas). Os resultados indicaram que não houve diferenças significativas $(p<0.05)$ para ambos os tempos, chancelando a recomendação da utilização do tempo de 2 horas na agricultura familiar.

Tabela 1. Valores médios ( \pm desvio-padrão) de triplicatas dos percentuais de cinzas, fibras, lipídios, proteínas, carboidratos e valor energético (\%), para três tempos de desidratação da polpa da beterraba conforme in natura e não conforme à comercialização

\begin{tabular}{|c|c|c|c|c|c|c|}
\hline Constituintes & & Conforme & & Não & Conforme & \\
\hline $\begin{array}{c}\text { Tempo de } \\
\text { Desidratação }\end{array}$ & $5 \mathrm{~h}$ & $7 \mathrm{~h}$ & $9 \mathrm{~h}$ & $5 \mathrm{~h}$ & $7 \mathrm{~h}$ & $9 \mathrm{~h}$ \\
\hline Cinzas & $6,6 \pm 0,17$ & $6,6 \pm 0,10$ & $7,14 \pm 0,37$ & $5,9 \pm 0,23$ & $6,3 \pm 0,43$ & $67 \pm 0,21$ \\
\hline Fibras $^{*}(5,9)$ & $11,6 \pm 0,96$ & $14,9 \pm 0,21$ & $20,97 \pm 1,37$ & $10,8 \pm 0,51$ & $13,5 \pm 0,82$ & $20,1 \pm 1,25$ \\
\hline Lipídios & $2,3 \pm 0,05$ & $2,9 \pm 0,04$ & $3,61 \pm 0,09$ & $2 \pm 0,06$ & $2,2 \pm 0,05$ & $2,6 \pm 0,08$ \\
\hline Proteínas ${ }^{*}(5 / 9)$ & $12,2 \pm 0,35$ & $13, \pm 0,15$ & $14,15 \pm 0,16$ & $12 \pm 0,41$ & $13 \pm 0,24$ & $13,2 \pm 0,36$ \\
\hline Carboidratos & $44,5 \pm 1,56$ & $46,7 \pm 0,62$ & $40,76 \pm 0,96$ & $44,7 \pm 0,73$ & $48,1 \pm 1,04$ & $43,3 \pm 1,52$ \\
\hline
\end{tabular}

* diferença significativa $(p<0.05)$. Laboratório de Tecnologia de Produtos Vegetais, Universidade de Santa Cruz do Sul - UNISC, Santa Cruz do Sul, de abril a setembro de 2014.

Entre os resultados das cinzas obtidos na composição centesimal relacionados aos tempos testados, o mais alto foi de 7,1\% em 7 horas e o menor de 5,5\% em 2 horas de secagem. Estes valores se assemelham com as farinhas apresentadas pela CNNPA, que variam de 1,0\% para a farinha de milho a 6,0\% na farinha de amendoim e soja parcialmente desengordurada (BIANCHINI et al., 2014).

Segundo Lopes et al. (2011), em comparação com a farinha de trigo, a farinha de beterraba tem cinco vezes mais fibras e quase 25 vezes mais minerais. A beterraba in natura possui baixas concentrações de fibras $(3,4 \%)$ devido ao alto teor de água de 89,2\% (TACO, 2011), comparando com a beterraba desidratada: 14,9\% e $21,0 \%$ (7 e $9 \mathrm{~h}$, respectivamente) e $16,1 \%$ e $24,3 \%$ ( $2 \mathrm{~h}$ e $5 \mathrm{~h}$, respectivamente). 
Farinhas com altos teores de fibras são recomendáveis para inserção em alimentos, pois a fibra atua principalmente na parte superior do trato gastrointestinal, mais especificamente no estômago e no intestino delgado onde ocorrem a digestão e absorção dos nutrientes, contribuindo para a normalização da funcionalidade do processo digestivo de alimentos ingeridos e da absorção de nutrientes, auxiliando ainda na prevenção de disfunções digestivas (ARAÚJO FILHO et al., 2011).

$O$ percentual de proteínas encontrado na farinha atende aos padrões da Portaria $\mathrm{n}^{\circ}$ 354/1996 (ANVISA, 1996), que classifica a farinha de trigo como sendo especial para uso doméstico, aquela com o percentual de proteínas superior a $7 \%$ para base seca. Considerando os valores obtidos para os tempos e cominuições testadas nesse trabalho, que variaram entre $10 \%$ a $14 \%$, foi verificado que estavam de acordo com os parâmetros estabelecidos. Ainda comparando com a farinha de centeio integral, que apresenta um percentual de proteínas de 12,1\% (FRANCO, 1998), os valores da farinha da beterraba ficavam acima, tornando-a mais nutritiva.

\subsection{ANÁLISE SENSORIAL DA MASSA DE TALHARIM COM 25\% DE FARINHA DE BETERRABA ORGÂNICA RALADA NÃO CONFORME}

Os resultados indicaram que $50 \%$ daqueles que experimentaram gostaram muito do sabor, 33,4\% gostaram ligeiramente e 16,6\% acharam indiferente o sabor da massa (Figura 4). As opções "desgostei ligeiramente" e "desgostei totalmente" não foram votadas. Desta forma, concluiu-se que a massa de talharim feita com $25 \%$ de farinha de beterraba orgânica não conforme apresentou um elevado grau de aceitabilidade pelo potencial público adulto consumidor. 


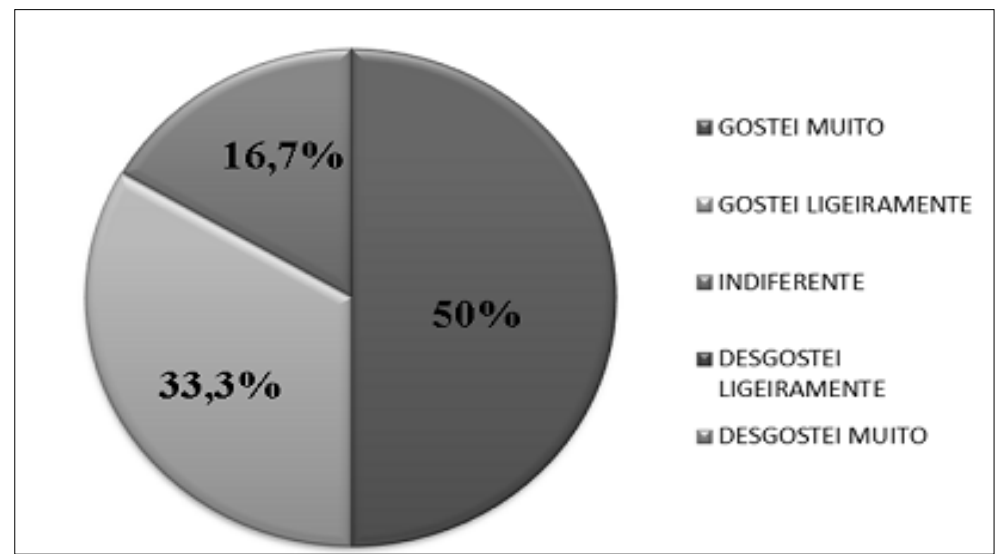

Figura 4. Análise sensorial hedônica verbal de 5 pontos (BRASIL, 2006) da massa de talharim elaborada com $25 \%$ de farinha de beterraba orgânica ralada não conforme à comercialização, adicionada a 75\% de farinha de trigo, em público adulto de diferentes idades $(n=12)$. Agroindústria da Agricultura Familiar Santa Isabel, Comunidade Santa Lúcia, Ibarama (RS), novembro de 2014.

\section{CONSIDERAÇÕES FINAIS}

Beterrabas não conformes à comercialização constituem uma alternativa promissora para a fabricação de farinhas e elaboração de massas com alto valor nutricional, evidenciado pela análise da composição centesimal e pelo alto índice de aceitabilidade na análise de palatabilidade (sabor) por público adulto potencial consumidor, sobretudo se considerada a utilização de beterrabas oriundas dos sistemas de produção de base ecológica praticadas em unidades de produção agrícola familiar.

Dos pontos de vista social, econômico e ambiental, a transformação de vegetais não conformes e sua incorporação na alimentação humana na forma de farinhas é uma maneira de produção diferenciada que utiliza tecnologias simples, utilizando os saberes e práticas tradicionais, passadas de geração para geração "saber fazer", tornando-se fonte de renda para as agroindústrias familiares com subprodutos de alto valor nutricional, incrementando o desenvolvimento local, além de contribuir à sustentabilidade ambiental rural, através da reutilização de resíduos vegetais orgânicos. 


\section{REFERÊNCIAS}

ABREU JUNIOR, C. H. et al. Uso agrícola de resíduos orgânicos potencialmente poluentes: propriedades químicas do solo e produção vegetal. Tópicos Ci. Solo, v. 4, p. 391-470, 2005.

ANVISA. Agência Nacional de Vigilância Sanitária. Legislação. Portaria no 354, de 18 de julho de 1996. Diário Oficial da União, de 22 jul. 1996, Seção 1. Disponível em: < http://www.anvisa.gov.br/anvisalegis/portarias/354_96.htm>. Acesso em: 09 out. 2014.

ARAÚJO FILHO, D. G. et al. Processamento de produto farináceo a partir de beterrabas submetidas à secagem estacionária. Acta Scientiarum. Agronomy, Maringá, v. 33, n. 2, p. 207-214, 2011.

BASSI, C. Consumo certo: dicas para aproveitar o melhor que a beterraba tem a oferecer: o poder da beterraba. [s.l.;s.n.], Ano 1, n. 1, 2014.

BIANCHINI, M. G. A.; BELEIA, A. D. P.; BIANCHINI, A. Modificação da composição química de farinhas integrais de grãos de amaranto após a aplicação de diferentes tratamentos térmicos. Ciência Rural, Santa Maria, v. 44, n. 1, p. 167-173, jan. 2014.

BRASIL. Resolução $\mathrm{n}^{\mathrm{o}} 12$ de 1978 . Normas técnicas especiais relativas a alimentos (e bebidas) para efeito em todo território brasileiro. Comissão Nacional de Normas e Padrões para Alimentos (CNNPA). Diário Oficial da União, 24 jul. 1978.

BRASIL. Lei $\mathrm{n}^{\mathrm{O}}$ 12.305, de 02 de agosto de 2010. Política Nacional de Resíduos Sólidos (PNRS). Presidência da República, Casa Civil. Diário Oficial da União, Brasília, 2 ago. 2010.

BRASIL. Decreto $\mathrm{n}^{\mathrm{0}}$ 6.268, de 22 de novembro de 2007. Regulamenta a Lei $\mathrm{n}^{0}$ 9.972, de 25 de maio de 2000. Presidência da República, Casa Civil. Diário Oficial da União, Brasília, 22 nov. 2007.

CALLEGARI-JACQUES, S. D. Bioestatística: princípios e aplicações. Porto Alegre: Artmed, 2006. 
CAMARGO, R. A. L.; BACCARIN, J. G.; SILVA, D. B. P. O papel do Programa de Aquisição de Alimentos (PAA) e do Programa Nacional de Alimentação Escolar (PNAE) no fortalecimento da agricultura familiar e promoção da segurança alimentar. Temas de Administração Pública, v. 8, n. 2, 2013.

CECCATO, C.; BASSO, C. Avaliação das perdas de frutas, legumes e verduras em supermercado de Santa Maria - RS. Disc. Scientia - Série: Ciências da Saúde, Santa Maria, v. 12, n. 1, p. 127-137, 2011.

COSTA, K. Logística integrada reduz perdas do campo ao consumidor: planejamento é a principal saída para a redução do desperdício de alimentos. ECOD. 2013. Disponível em: <http://www.mobilizadores.org.br/wp-content/ uploads/2014/05/do-campo-cidade-solucoes-para-o-desperdcio-de-alimentos.pdf $>$. Acesso em: 15 nov. 2014.

FAO. Organización de las Naciones Unidas para la Alimentación y la Agricultura. Pérdidas y desperdicios de alimentos en América Latina y el Caribe. Jun. 2014.

FRANCO, G. Tabela de composição química dos alimentos. 9. ed. [s.l.]: Atheneu, 1998.

GUIMARÃES, A. N.; SEIBEL, N. F. Aproveitamento dos descartes vegetais em produtos para a alimentação humana. In: SEMINÁRIO DE INICIAÇÃO CIENTÍFICA E TECNOLÓGICA- SICITE, 14., 2009. Anais... [s.l.]: UTFPR, 2009.

IBGE. Instituto Brasileiro de Geografia e Estatística. Censo Agropecuário 2009. Disponível em: < http://www.ibge.gov.br/home/estatistica/economia/ppm > Acesso em: mar. 2014.

INSTITUTO ADOLFO LUTZ. Métodos físico-químicos para análise de alimentos. 4. ed. São Paulo: [s.n.], 2008.

LOPES, S. B. et al. Aproveitamento do resíduo gerado na produção de mini beterrabas para a produção de farinha. Comunicado técnico Embrapa 80, Brasília, dez. 2011. 
MIGUEL, A. C.A. et al. Aproveitamento agroindustrial de resíduos sólidos provenientes do melão minimamente processado. Ciênc. Tecnol. Aliment., Campinas, v. 28, n. 3, p. 733-737, jul./set. 2008.

NEVES, M. V. M.; LIMA, V. L. A. G. Avaliação sensorial e caracterização físico-química de néctar de acerola adicionado de extrato comercial de própolis. Alim. Nutr., Araraquara, v. 21, n. 3, p. 399-405, jul./set. 2010.

PARK, K. J.; ANTONIO, G. C. Análises de materiais biológicos. São Paulo: UNICAMP, 2006.

PICOLI, L. R. Transição agroecológica: os casos da Ecovale e da Coopaecia - RS. 2013. Dissertação (Mestrado em Desenvolvimento Regional) - Universidade de Santa Cruz do Sul, Santa Cruz do Sul, RS.

SANTOS, F. et al. Avaliação da inserção de alimentos orgânicos provenientes da agricultura familiar na alimentação escolar, em municípios dos territórios rurais do Rio Grande do Sul, Brasil. Ciência \& Saúde Coletiva, v. 19, n. 5, p. 1429-1436, 2014.

SCHEEREN, P. Aproveitamento de maçãs não conformes a comercialização na elaboração de pães. 2011. Monografia (Graduação em Química Industrial) - Centro Universitário Univates, Lajeado, RS.

SEBRAE - Serviço Brasileiro de Apoio às Micro e Pequenas Empresas. Beterraba: saiba como cultivar hortaliças para colher bons negócios. [s.l.]: Sebrae, 2011. (Série Agricultura Familiar). Disponível em: <www.sebrae.com.br/setor/horticultura $>$. Acesso em: nov. 2014.

SGARBI, J. et al. Agroindústria familiar rural: contribuições para o desenvolvimento agroecológico. Pelotas: Centro de Apoio ao Pequeno Agricultor, 2007.

TACO. Tabela brasileira de composição de alimentos. 4. ed. Campinas: NEPA/ UNICAMP, 2011. 
TIVELLI, S. W. et al. Beterraba: do plantio à comercialização. Campinas: IAC Instituto Agronômico de Campinas, 2011. (Série Tecnologia APTA. Boletim Técnico IAC, 210). Disponível em: < http://www.iac.sp.gov.br/publicacoes/publicacoes online/pdf/bt_210.pdf > . Acesso em: 20 set. 2014.

ZANATTA, C. L.; ABITZ, C.; ETHUR, E. M. Avaliação físico-química e microbiológica de farinhas obtidas a partir de vegetais não conformes à comercialização. Alimentos Nutricionais, Araraquara, v. 21, n. 3, p. 459-468, 2010.

ZIMMERMANN, L. O. G. et al. Avaliação físico-química e reológica das principais farinhas de trigo comercializadas em padarias do município de Cascavel. In: SEMINÁRIO INTERNACIONAL DE CIÊNCIA, TECNOLOGIA E AMBIENTE, 2009. Anais... Cascavel, PR: UNIOESTE.

Recebido em: 25 de março de 2015 Aceito em: 21 de janeiro de 2016 